\title{
Exploring the Relationship Between Nutrition and Academic Learning among Students of Samtse College of Education
}

\author{
Dorji Tenzin \\ Dagana Dzongkhag, Ministry of Education, Bhutan \\ Kinley Seden \\ Samtse College of Education, Bhutan \\ Nima Dorji \\ Sarpang Dzongkhag under Ministry of Education, Bhutan
}

\begin{abstract}
The study was conducted to explore the existence of relationship between the academic learning of college students and their nutritional diets receive from the college mess. The data was collected through a Student Food Survey (SFS) $(\mathrm{N}=135)$ and structured interview $(\mathrm{N}=6)$ among college students who had the lived experience of having meals from the college mess. The survey data was analyzed for descriptive and correlational analysis using SPSS. Similarly, the interviews were transcribed and analyzed into three major themes: food quality, eating practices, and recommendations. The data revealed that food quality and nutritional diets served in the mess affect students' eating habits and their academic learning. Further, the findings from survey indicate a significant positive correlation between food quality and academic learning of students. The study concluded by stating that nutritional deficiencies contribute to lack of academic concentration and therefore, recommends the college management devise strategic interventions to improve food quality in the mess.
\end{abstract}

Key words: Relationship, nutritional diets, academic learning, food quality, and eating habits

\section{Introduction}

Anemia and stunting (low length or low height-for-age) are the most evident consequences of under nutrition in most of the country. It was reported that in Bhutan, stunting has a prevalence of 33.5 percent and anemia affects 54.8 percent of women and 80.6 percent of children, which is recorded as the highest in the world (Atwood, et al. (2014). Further, health problems and non-communicable diseases related to lack of balanced diets, micronutrient deficiencies, and lifestyle changes continue to pose challenges to achieve 'zero hunger' which is one of the Sustainable Development Goals (SDGs). 
As a consequence of stunting and other nutrition-deficient diseases, children face diverse functional consequences such as poor cognition and educational performance, loss of productivity, and increase in weight which puts more risk to nutrition-related chronic diseases. This study took place at one of the Education Colleges in Bhutan. The teacher students in the college are made up of different cultures with different preferences of foods at different times.

Yet, the college serves all three meals to the teacher students residing as boarders within the campus to maintain uniformity. However, it was observed that teacher students of the college were served with easily available food items instead of a balanced diet which might contribute to students' poor attitude towards their daily learning. Likewise, it was observed that students developed poor eating habits due to the appearance, taste, smell, texture, and quality of the food served in the kitchen.

Additionally, it is uncertain that the proper nutritional guide is followed in providing nutrition-rich food items and adequate amount of nutrients necessary for good health (nutritional diets) to the teacher students. Further, teacher students preferred eating their own choice of food (fast and junk foods) available within the campus than visiting the college mess. Thus, the strong presence of having so many students skipping meals and the lack food quality in the college mess led to the decision that this college would be an excellent area to conduct research on how nutritional diets have an impact on students' academic learning and performance. Moreover, no such studies have been conducted within the Bhutanese tertiary Education setting. Hence, given this issues and gap, this study aims to explore the relationship between students' academic learning and their nutritional diets received from the college mess.

\section{Research question:}

1. What is the relationship between nutritional diets and the academic learning of college-going students?

\section{Sub-questions}

a) What are the perceptions of students on quantity and quality of food in mess?

b) What are the perceptions of students on nutrition of food in the mess?

c) What are the eating habits of students in the mess?

d) How do students feel about the importance of good nutritional diets (eating a balanced and healthy diet) and their learning?

\section{Literature Review}

Nutrition and Cognition 
Studies have concluded that dietary habits affect normal brain functions. Growden and Wurtman (1980) suggested that the brain is not an autonomous organ, instead, it is affected by the nutrition, the concentration of amino acids, and choline (in the blood) which lets the brain create and use neurotransmitters. Colby-Morley (1981) asserted that what we eat directly influences the brain functioning. For example, Rausch (2013) reported that having a healthy, balanced diet improves brain capacity, maximizes cognitive capabilities, and improves academic performance in school-age children.

In addition, a direct correlation between nutrition and performance of children was found amongst the school aged children. Wood (2001) concluded that nutrition has a vital role in the cognitive functioning of children. Additionally, the study also found the role of iron in brain function. It was reported that children with low test scores corresponded to a lower level of irons in their bodies, or rather, children with iron deficiency (Wood, 2001).

Similarly, it was confirmed that the zinc nutrient has a role with memory and students' abilities to remember everyday words. Likewise, a deficit of specific nutrients such as vitamins A, B6, B12, C, iron, zinc, and calcium are also associated with lower grades and higher rates of absenteeism and tardiness among students (Bacsh, 2010; Kleinman et al., 2002; Taras, 2005). Moreover, hunger, due to insufficient foods, resulted in poor grades, high absenteeism, and an inability to focus (Kleinman et al., 2002; Taras, 2005). In addition, it also reiterated that poor nutrition can leave the students more susceptible to illness like headaches and stomachaches, resulting in absenteeism (Brown et al., 2008).

Erickson (2006) mentioned that substances found in all the food are important for brain development and function. The study pointed out that lack of protein will result in Protein Energy Malnutrition (PEM) which leads to poor performance and younger children become lethargic, which affects their social and emotional development. Furthermore, the lack of carbohydrates may cause dizziness and mental confusion which would eventually affect student performance. According to the literature (Bellisle, 2004), Sorhaindo \& Feinstein, 2006)), students who are more exposed to proteins, carbohydrates, and glucose have improved cognition, concentration, and energy levels.

\section{Nutrients and Learning}

Proper nutritional support is required to allow the brain to function at its highest ability and to enhance learning. It requires a proper adaptation of the Food Guide Pyramid to help children reach their potential. Wolfe et al. (2000) demonstrated that nutrition affects students' thinking skills, behavior, and health that impact academic performance. According to Busch et al. (2014), healthy nutrition and sports participation have positive impacts on students' 
academic performance.

Similarly, Wolfe et al. (2000) also highlighted the negative impact of skipping meals. They concluded that children, who eat a good breakfast, have better performance scores as eating breakfast helps in improving attention, retrieving information more quickly and accurately, make few errors in problem-solving activities and concentrate better and also perform better when asked to do complex tasks. In addition, Pollitt and Mathews (1998) and Rampersaud et al. (2005) stated that children skipping breakfast have low academic performance due to the failure in important areas such as alertness, attention, memory, processing of complex visual display and problem solving. Further, students who have access to nutrition, particularly breakfast, can have enhanced psychological well-being, reduced aggression and school suspensions, and decreased disciplinary issues (Brown et al., 2008; Murphy et al., 2005).

Further, Lahey and Rosen (2002) also concluded that students, who showed poor academic performance, had inadequate fruits and vegetable intake as compared to those who had adequate intake of fruits and vegetables. According to MacLellan et al. (2008), lack of adequate consumption of foods such as fruits, vegetables, or dairy products is associated with lower grades among students.

The study also found that students participating in the United States Department of Agriculture (USDA) School Breakfast Program (SBP) exhibited increased academic grades and standardized test scores, reduced absenteeism and improved cognitive development (Bradley \& Green, 2013). Similarly, the study on $5^{\text {th }}$ grade students demonstrated that students with low nutritional diets performed worse in a standardized literary assessment (Florence et al., 2008).

\section{Eating habits and academic achievement}

There was a small association between a healthier dietary intake and higher academic achievement and vice versa in university students (Whatnall et al. 2019). Similarly, the studies (Mora et al., 2019; Lundqvist et al., 2018; So, 2013) showed positive correlation between the eating habits and academic achievement among adolescents. In addition, there was a relationship between the regular consumptions of the three main meals, breakfast, lunch, and dinner and better academic performance (Kim et al., 2016; Overby et al., 2013). Further, food consumption that is rich in essential nutrients is significantly associated with good academic performance (Kim et al., 2016; Pearce et al., 2018).

Similarly, food can make students become more focused and can ultimately affect their academic performance (Drummond \& Brefere, 2001). Nevertheless, it was concluded that 
students who are dissatisfied with the service and quality of food in the universities will choose the off-campus dinning (Lee \& Lyu, 2019).

\section{University food service attributes}

Since this study is for university students, evaluating the role of on-campus dining service is critically important. Klasen et al. (2005) stated that food service is a fundamental factor that influences students' satisfaction. Concerning the food quality service, Andaleeb and Caskey (2007) mentioned that the improvement in food quality would retain the students availing the food services provided in the campus. Further, Raman and Chinniah (2011) noted that varieties and diversities of food give students a sense of home while on the campus. The most common complaints regarding the food services in the universities in Malaysian were poor ambience, lack of food choices, and low quality of food (Klasen et al. 2005).

\section{Methodology}

A convergent parallel mixed method guided by the pragmatism paradigm was employed for the study. This paradigm enables the researcher to focus on a research problem in social science and acquire knowledge about the problem with an employment of both qualitative and quantitative approaches (Tashakkori \& Teddlie, 2010). Further, it allows the researcher to gather more reliable and authentic information (Creswell, 2003).

A Student Food Survey (SFS) was adapted to collect the data which was developed by Malki (2018). This student food survey was developed in 2018 for the thesis paper which was submitted for the partial fulfillment of the requirements for the degree of masters of arts in education in California State University, San Marcos. It has eleven items and one open-ended question. This survey was found relevant and appropriate to be adapted as it covered a wide range of aspects such as quality of food supplied, eating habits and its relationship to learning.

Similarly, the student survey consisted of a 4 level Likert-scale and supplied openended questions. The survey covered a variety of areas such as quality of food offered at the college, their usual eating habits, and what impact that might have on learning. Further, as a supplement to quantitative findings, a semi-structured interview was administered.

A semi-structured interview was conducted to enable the participants to discuss their interpretations of campus food, their study habits and how they regard their university situations from their own point of view. This approach gave adequate, reliable, and comparative qualitative data in terms of quality of food served, eating habits of the teacher students, and their perceptions of its impact of their academic performance.

The interview questions were based on the pre-determined themes such as eating habits, 
quality of food served, experiences and perceptions on relation between nutrition and academic learning. These themes guided the researcher in understanding and acquiring information through prompting and rephrasing.

Similarly, Cohen et al. (2007) mentioned that this approach helps the researcher in understanding the situations more thoroughly by prompting, probing, and pressing for clarity, rephrasing and summarizing whenever necessary (Cohen et al., 2007).

Prior to the interview, the researcher stressed that - anonymity would be maintained by using pseudonyms. The interview lasted for 10-15 minutes and was conducted to gather each participant's experiences, feelings, trends and opinions about the food served in the college mess. Since teacher students have responded to the open-ended questions on the same issues in the SFS, the time allocated for semi-structured was kept short. The study done by Adams (2015) on conducting a semi-structured interview mentioned that proposing a too long period for the interview can prompt an outright refusal.

\section{Participants}

The boarding teacher students of Samtse College of Education, under the Royal University of Bhutan (RUB) took part in the research exclusively in generating data both quantitatively and qualitatively. More than half of the participants have been taking the meals from the college on a regular basis for more than 3 years and some for 1 year respectively.

The participants for the survey questionnaires as well as for the semi-structured interviews were selected based on the convenience sampling (non-probability sampling) method as it allows the researcher to choose based on the convenience and availability of participants in the surrounding environment (Creswell \& Creswell, 2018). A total of 135 (75 males, 60 females) teacher students participated for the SFS questionnaires and 6 ( 3 females, 3 males) participated in the semi-structured interview.

To avoid unexpected circumstances and for the smooth flow of the study in the college, an approval letter was asked from the college research committee. Moreover, to respect the rights and values of the participants, they were assured with the anonymity and confidentiality of the findings. Similarly, prior to the administration of survey questionnaires and conduct of interviews, the researchers briefed the participants on purpose of the research and their rights to withdraw if they have any problem in the process of the study. Subsequently, the researcher distributed informed consent form to only those interested individuals and moreover, the participants' confidentiality was protected through the use of pseudonyms. 
A college premises has a dining facility for the students residing in the hostel. The mess caters to more than 500 students and serves breakfast, lunch, evening tea, and dinner every day accordingly with the food menu adopted. In fact, a group of volunteered students run the mess on a monthly basis with the amount collected from students' monthly stipend. These groups of students are responsible for the functioning of the mess and proper supervision of cooks and other people engaged in the kitchen. Exclusively, they maintain a check and balance of the mess stores, monthly expenditure statements of the mess and the issuance of provisions with proper record book.

\section{Data Analysis}

The quantitative data were analyzed for descriptive and correlational analysis using SPSS 22.0. Pearson correlation coefficient was used to determine the relation between nutrition and learning. Similarly, for the qualitative data, Braun and Clarke's (2006) six-phase thematic analysis was adopted to analyze and evaluate the perceptions and experiences of the teacher students regarding nutritional diets they receive from the college mess and their relationship with academic achievement. Thus, the Braun and Clark (2006) six-phase thematic analysis approach was employed in the study in analysing the qualitative data.

\section{Quantitative data analysis}

Thirty-eight items were used in the survey questionnaires. The data collected in each item was measured using the Likert-type rating scales in four different levels of agreement: Strongly Disagree $(\mathrm{SD})=1$; Disagree $(\mathrm{D})=2 ;$ Agree $(A)=3$ and Strongly Agree $(\mathrm{SA})=4$. To determine the overall ratings, the interval mean mid-scores was calculated, based on the number of interval levels each Likert-type scale were composed of, by using the following equation:

$$
\text { Interval }=\frac{\text { Highest Level score }- \text { Lowest level score }}{\text { Number of Levels }}
$$

This score range was divided into 5 categories of agreement level: Strongly disagree, Disagree, Slightly Agree, Agree, and Strongly Agree level as shown in Table 1. 


\section{Table 1:}

Criteria for level of Agreement on Nutrition and Academic learning

Mean Score

$1.00-1.80$

$1.81-2.60$

$2.61-3.40$

$3.41-4.20$

$4.21-5.00$
Agreement Level

Strongly Disagree

Disagree

Slightly Agree

Agree

Strongly Agree

\section{Students' Perception on Quantity and Quality of the Food}

Table 2 shows student's level of agreement on nutritious food provided in the college dining hall. According to the data, students slightly agree that they get enough food in the mess, however, they also claim that they get hungry between meals $(M=2.912, S D=0.488)$. This indicates that students have access to larger quantity of food, however, the quantity did not suffice their hunger. On the other hand, the majority of students disagree that the college dining hall provided good quality meal in the mess $(M=2.377, S D=0.512)$. Further, they also denied that food offered in the college mess were Nutritious $(M=2.017, S D=0.549)$.

\section{Eating Habits of Students}

Though students feel that they are not provided with good quality food in the dining hall, they do agree that they take meals from the mess $(M=2.65, S D=0.5)$. However, students do not agree that they are served with nutritious food in the mess $(M=2.54, S D=0.42)$.

\section{Nutritious Diet and Academic Learning}

It was revealed from the data (Table 2) that students agree that their learning performance in the class is usually affected by the food served in the mess. On top of that, they asserted that nutrition plays an important role in their academic learning $(M=2.95, S D=0.376)$. Thus, students indicated that the food served in the mess has less nutritional value, thereby, impacting their learning.

Table 2:

Students Agreement level on food nutrition served in Samtse College mess

\begin{tabular}{lccccc}
\hline & N & Minimum & Maximum & Mean & $\begin{array}{c}\text { Std. } \\
\text { Deviation }\end{array}$ \\
\hline $\begin{array}{l}\text { Hunger and Quantity of } \\
\text { Food }\end{array}$ & 135 & 1.70 & 4.00 & 2.91 & .488
\end{tabular}


JISTE, Vol. 25, No. 2, 2021

Meal Quality and

Enjoyment

Dining Room

Foods and Nutrition

Eating Habit

Nutrition and Learning

Nutrition and Health
135

1.00

135

135

135

135

135
2.00

1.00

1.50

1.67

1.60
3.70

3.80

3.60

4.00

4.00

3.80
2.38

.513

Valid N (listwise)

135

Similarly, Pearson correlation analysis test (Table 3) shows that there exists significant positive correlation between students' perception towards food nutrition served in the college mess and their learning experience at Samtse College of Education. Specifically, as shown in the table, there exists a significant weak positive correlation between students' learning experience and their perception towards quantity of food served in the college mess $(r=0.206$, $p=0.016$ ). Similarly, there exists a significant weak positive correlation between students' learning experience and their perception toward quality of food served in the mess $(r=0.249$, $p=0.004)$. It was also observed that students' eating habit in the college mess has significant moderate positive relation with students learning experience $(r=0.306, p=000311)$. Further, it was found that there exists positive weak correlation between students' perception towards nutritious food and their learning experience $(r=0.181, p=0.036)$.

\section{Table 3:}

Relationship between food nutrition and students learning

\begin{tabular}{|c|c|c|c|c|c|c|c|}
\hline & & 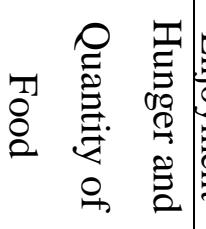 & 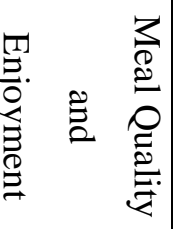 & 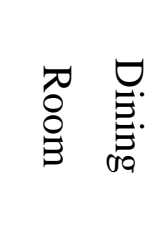 & 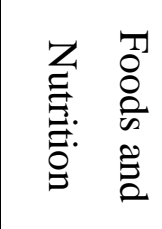 & 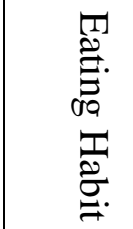 & 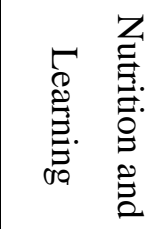 \\
\hline \multirow{2}{*}{$\begin{array}{c}\text { Nutrition } \\
\text { and Learning }\end{array}$} & $\begin{array}{l}\text { Pearson } \\
\text { Correlation }\end{array}$ & $.206^{*}$ & $.249^{* * *}$ & $.246^{* *}$ & $.181^{*}$ & $.306^{* *}$ & 1 \\
\hline & Sig. (2-tailed) & .016 & .004 & .004 & .036 & .000 & \\
\hline
\end{tabular}

Note: Correlation level,0.00-0.25, Weak; 0.26-0.50, Moderate; 0.5-0.75, Strong;0.761.00, Very Strong. Adapted from Sugiyono (2013).

Qualitative analysis

The information gathered from the interview $(\mathrm{N}=6)$ and survey open-ended questions 
$(\mathrm{N}=135)$ was constrained into two major categories such as food quality and eating habits in the dining hall.

\section{Food Quality}

It was understood that the kind of foods served in the mess do not meet the nutritional requirement of the students and the food quality in the mess has no significant change throughout the year.

The food provided in the mess is less nutritious and it's uncooked most of the time. (S1)

It's quite unhealthy and also, I feel bad for myself for not being able to give nutritious food to myself. (S2)

Moreover, it was revealed that the food served in the dining hall lacked varieties. The same items were served in all three meals of the day. For instance, potatoes curry was found to be served regularly, while green vegetables were rarely served. However, on special days, the greens were served. Although fruits and vegetables are of a great source of fiber, antioxidants, vitamins and minerals, students asserted that fruits were only served for a countable number of days or hardly part of the meal. Further, the findings also revealed that students were served uncooked food quite often which prevented them from eating resulting in hunger and loss of appetite subsequently.

Similarly, a few of the students mentioned that the quality of food provided in the mess does not last for longer durations leading to hunger immediately after the meals. This could be because students are hardly served with food rich in nutrients. Instead, students are served with high calorie food which offers little or no value nutritional value. Students stated:

Food is often of bad quality. And curry is of not good taste either. I feel hungry right after stepping out of the mess. (S3)

Eating in the mess feels like not eating at all because after eating from the mess, I feel hungry while reaching back to the room. (S4)

Eating practices in the mess

Eating in the mess has become quite challenging for the students for numerous reasons. When students were asked, what makes you eat in the mess? They exposed various reasons. Students informed the researchers that they enjoy having meals in the mess as they get to interact and eat together with their friends. Similarly, it was understood that there are few other reasons that compel students to involuntarily visit the mess for meals. Firstly, lack of money. Unlike in other countries, Bhutanese students do not have the privilege to generate income or make money by working part-time which makes them to solely depend on their stipend. As a result, the college mess becomes the only source of food for their survival as it at least suffices 
their hunger and keeps their stomach filled as stated in this excerpt:

Eating from the mess is just for the sake. I eat for the sake of filling my tummy but it's no use because after half an hour or so I feel hungry. I still eat it with the fear that might get TB. (S5)

The health issues such as fatigue, kidney stress, low blood pressure, headache, constipation and nausea, and dizziness are some of the most common diseases found in people who skipped meals. Hence, although the benefits derived from the mess is zero, they eat from the mess to prevent themselves from such effects and to keep their stomach full. There are no evidences that filling the stomach has helped to overcome these issues, however, students do it with the belief that it may help to a certain extent.

Additionally, another student said that the very reason for eating in the mess is to gain energy to concentrate during class hours. This is in contradiction to other research which points out that lack of nutrition or nutritional deficiencies in foods leads to anemia thereby causing fatigue. The student stated:

Since we have class from morning till evening to concentrate in class it's important is

to take meals, if not, the hunger doesn't let us concentrate. (S6)

However, it is questionable whether just consuming food that has no nutritional would help gain energy and allow the students to stay focused in the class. Nonetheless, mess management must find ways to substitute carbs with at least food that would provide some form of protein, fibre and antioxidants.

In contradiction, it was mentioned there are various factors that stop students from eating in the mess. When students were asked, what prevents you from eating in the mess? Students indicated some of the common reasons as lack of quality of food, same menu or lack of varieties of food and vegetables, overcooked or uncooked foods, size of vegetables and bad taste of curry. Further, one of the students said, "The uncooked vegetables, the same menu for the number of days, and the piece of glass that was found on my friend's plate made us more cautious and avoided the meals irrespective of how they taste”. Similarly, a few of them even revealed that the food served from the mess does not last long and quite often leads to hunger immediately after the meals which eventually resulted in them looking for other fast foods or junk items. It was quite awful to know that some of them have even identified foreign bodies (glass pieces and stones) in their food, which further prevented them from risking their lives by eating it. Hence, proper mechanisms need to be put in place to avoid such mishap that might pose risk to students' health. 


\section{General suggestions from the students}

It was learned that proper monitoring is required to ensure that quality and nutritious food is served to the students since the willingness of the students to eat in the mess is entirely dependent on the quality and nutritional diets served, not the quantity. It was mentioned that such practices can reduce the food wastes in the mess. Likewise, the students have suggested management body and mess coordinators to kindly focus on providing nutrient-rich foods including milk, meat, and egg, vegetables, and fruits and focus on a balanced diet instead of serving the same items throughout the seasons. In contradiction, students also emphasized that students do not have to be served with meats and eggs all the time but preparing what is available in the best way possible is required.

The presentation of food must also be taken into consideration and monitored frequently as presentation eventually indicates the sanitation and hygiene of the meals. Most of the students interestingly pointed out that the green veggies were overcooked, leading to the loss of nutrition. Further, passion and interest of the people involved in cooking plays a vital role in the quality of food served, irrespective of their experiences. However, it was observed that those working in the mess lacked interest and motivation to work. Thus, the management must develop a plan to ensure that those people possess such qualities which would eventually result in making a huge difference including the quality of food being served and provide a form of motivation for the enhancement of the preparers' interests. In this regard, we suggest cooks to be trained in order to enhance their cooking knowledge and skills.

\section{Discussion}

The findings from both the quantitative and qualitative data revealed that the food served in the college mess does not meet required quality and nutritional value. It was also revealed that students often get hungry in between the meals which eventually resulted in lack of concentration in the class. These findings were in sync with studies done by number of researchers that indicated that poor quality and less nutritional food may result in poor grades and inability to focus in the class and learning (Kleinman et al., $2002 \&$ Taras, 2005).

Similarly, Wolf et al, (2000) reported that nutritional diets students receive affects their thinking skills, behavior and health which has impact on students' learning and performance. Likewise, the current study also found that there was significant positive correlation between food nutrition and students learning experiences in Samtse College of Education. There exists a significant positive correlation between students learning experiences and their perceptions towards the quantity to food served. 
Moreover, the findings revealed that there was a significant positive correlation between the students' learning experiences and their perceptions on quality of food served. Further, it was found that there exists positive relation between student's perceptions towards nutritious food and learning experiences. These findings are consistent with the literature (Kim et al., 2016; Pearce et al., 2018) that the food consumption that is rich in essential nutrients is significantly associated with good academic performance. The researchers such as Kleinman et al. (2002) and Taras (2005) also supported the findings that insufficient food served affects the learning through higher rate of absenteeism and inability of focus.

Similarly, Wolf et al. (2002) and Bush et al. (2014) highlighted the importance of nutritional foods for the brain to function at its highest ability to enhance academic learning. The survey data found that there was significant positive relation between students' learning experiences and eating habits $(r=0.306, p=000311)$. These finding align with the findings of Rampersaud et al. (2005), who stated that children with poor eating habits have poor academic learning as well as performance due to the failure in alertness, attention and problemsolving skills. Similarly, this finding corroborates with the studies (Mora et al., 2019; Lundqvist et al., 2018; So, 2013) who found the positive correlation between academic learning and eating habits. Additionally, Brown et la. (2008) and Murphy et al. (2005) put forward that that students with better eating habits, particularly breakfast, can reduce aggression and suspensions and decrease disciplinary issues which would eventually contribute in better learning.

However, the findings from the open-ended questions and interview revealed various factors which prevent them from taking food in the mess such as poor quality of food, same menu, and existence of foreign bodies in the meals. This finding is consistent with the literature (Klasen et al. 2005) which concluded that poor ambience, lack of food choices, and low quality of food were some of the complaints regarding the food services in universities in Malaysia.T hese factors have largely attributed to students' inability to concentrate in the class, thereby hampering their academic learning.

\section{Conclusion and Recommendations}

This study focused on finding the relationship between nutritional diet and academic learning of college going students. The findings revealed that there exists a positive correlation between teacher students' perceptions about the quality and nutritional diets and their learning experiences. Additionally, the results indicated that those students who are exposed to poor quality and poor nutritional diets are more susceptible in developing poor learning habits and behaviour. 
Thus, the study illustrates the need to aid students in maintaining a healthy lifestyle and the management to review and develop plans to ensure that a balanced diet is served in the student dining hall. Moreover, we recommend the college administration to determine strategic interventions in the area of resource support and capacity development of cooks as such intervention would subsequently help the cooks in fostering their interest and enthusiasm in doing the work and simultaneously contributing to the well-being of college students and their learning.

This study is limited in terms of sample size. Therefore, the findings cannot be generalized to all Royal University of Bhutan (RUB) colleges. Thus, a further study on the same topic involving more sample sizes from RUB colleges is recommended.

\section{References}

Adams, W. C. (2015). Conducting semi-structured interview. Handbook of Practical Program Evaluation. 1-16.

Andaleeb, S. S., Caskey, A. (2007). Satisfaction with Food Services: insight from a college cafeteria. Journal of Foodservices Business Research. 10(2). 51-65.

Atwood, S. J., Nagpal, S., Mbuya, N. V., \& Laviolette, L. (2014). Nutrition in Bhutan: Situational Analysis and Policy Recommendations. World Bank Group.

Basch, C. E. (2010). Healthier students are better learners: A missing link in efforts to close the achievement gap. Comlombo University.

Bellisle, F. (2004). Effects of diet on behaviour and cognition in children. British Journal of Nutrition, 92(2), 227-232.

Bradley , B., \& Green, A. C. (2013). Do health and education agencies in the United States share responsibility for academic achievement and health? A review of 25 years of evidence about the relatonship of adolescents' academic achievement and health behaviours. Journal of Adolescents Health, 52(5), 523-532.

Brown, J. L., Beardslee, W. H., \& Pro-Throw-Stith, D. (2008). The impact of school breakfast on children's health and learning: An analysis of the scientific research. New York.

Busch, V., Loyen, A., Lodder , M., \& Schrijvers, A. (2014). The effects of adolescent health related behaviour on academic performance. A Review of Educational Research, 84(2), 245-274.

Cohen, L., Lawrence, M., \& Keith, M. (2007). Research Methods in Education (6 ed.). Routledge. 
Colby-Morley, E. (1981). Neurotransmitters and Nutrition. Orthomolecular Psychiatry, 12, 3843.

Creswell, J. W., \& Creswell, J. D. (2018). Research Design: Qualitative, Quantitative and Mixed Method Approaches (5 ed.). SAGE Publications Pvt. Ltd.

Drummond, K., Brefere, L. (2001). Nutrition for foodservice and Culinary Professionals. John Willey \& Sons, Inc: New York, USA.

Erikson, J. (2006). Brain food: The real dish on nutrition and brain function. WisKids Journal.

Florence, M. D., Asbridge, M., \& Veugelers, P. J. (2008). Diet quality and academic performance. Journal of School Health, 78(4), 209-215.

Growdon, J. H., \& Wurtman, R. J. (1980). Contemporary nutrition: Nutrients and neurotransmitters. New York State Journal of Medicine, 57.

Kim, S., Sim, S.,Park, B., Kong, I., Kim, J. H., Choi, H., (2016). Dietary habits are associated with school performance in adolescents. Medicine. 95(12).

Klassen, K., Trybus, E., Kumar, A. (2005). Planning food services for campus setting. International Journal of Hospitality Management.24. 579-609.

Kleinman, R. E., Hall, S., Green , H., Korzec-Ramirez, D., Patton , K., Pagano, M. E., \& Murphy, J. M. (2002). Diet, breakfast, and academic performance in children. Annals of Nutrition \& Metabolism, 46(1), 24-30.

Lahey, M., \& Rosen, S. (2002). Dietary factors affection learning behaviour. Retrieved from http://childrensdisabilities.info

Lee, K. A., Lyu, E. S. (2019). Importance-performance analysis (IPA) of university food service quality by customer group according to the foodservice satisfaction and customer loyalty. Journal of Korean Social Food Science and Nutrition.21. 389-405.

Lundqvist, M., Ennab-Voggel, N., Levin, L. A. (2018). effects of eating breakfast and social breakfast programmes on children and adolescents: a systematic review. Linkoping University Electronic Press.

MacLellan, D., Taylor, J., \& Wood, K. (2008). Food intake and academic performace among adolescents. Canadian Journal of Dietic Practice and Research, 69(3), 141-144.

Malki, A. (2018). Effects of Student Nutrition on Academic Performance. Student Nutrition on Academic Performance. 1-45.

Murphy, J. M., Drake, J. E., \& Weineke, K. M. (2005). Academics and breakfast connection pilot: Final report on New York's classroom breakfast project. New York.

Mora, J. I., Ventura-Vall-Llovera, C., Harnendez-Mosqueira, C. (2019). Level of physical activity, eating habits, and their relationship with academic performance in adolescent 
students at COMEDUC foundation, Chile. Journal of Physical education and Sport.19(4). 1-8.

Overby, N. C., Ludemann, E., Hoigaard, R. (2013). Self-reported learning difficulties and dietary intake in Norwegian adolescents. Scandinavian Journal of Public Health. 41(7). 754-760.

Pollitte, E., \& Mathews, R. (1998). Breakfast and cognition: An integrative summary. American Journal of Clinical Nutrition, 67(4), 804-813.

Raman. S., Chinniah, S. (2011). An Investigation on Higher Learning Students Satisfaction on Food Services on University Cafeteria. International Journal of Commercial IT Management. 1. 12-16

Rampersaud, G. C., Pereira, M. A., Girard, B. L., Adams, J., \& Metzl, J. D. (2005). Breakfast habits, nutritional status, body weight, and academic performance in children and adolescents. Journal of American Dietic Association, 105(5), 743-760.

Rausch, R. (2013). Nutrition and academic performance in school-age children the relation to obesity and food insufficiency. Journal of Nutrition and Food Sciences, 3(2).195 ref 11.

So, W. Y. (2013). Association between frequency of breakfast consumption and academic performance in healthy Korean adolescents. Iranian Journal of Public health. 42(1). 25

Sorhaindo, A., \& Feinstein , L. (2006). What is the relationship between child nutrition and school outcomes?[Wider Benefits of Learning Research Report No. 18]Center of Research on the Wider Benefits of Learning, Institute of Education, University of London.

Sugiyono. (2013). Metode Penelitian Kuantitatif Kualitatif dan R\&D. Alfabeta

Taras, H. (2005). Nutrition and student performance in school. Journal of School Health, 75(6), 199-213.

Tashakkori, A., Teddlie, C. (2010). SAGE Handbooks of Mixed Method on Social and Behavioural Research (second Ed). Thousands Oak, CA. Sage.

Whatnall, M. C., Patterson, A. J., Burrows, T. L., Hutchesson, M. J. (2019). Higher diet quality in university students is associated with higher academic achievement: a cross-sectional study. Journal of Human Nutrition and Dietetics. 1-8.

Wolfe, P., Burkman, A., \& Streng, K. (2000, March). The science of nutrition. Educational Leadership, 57 (6), 54-59.

Wood , M. (2001). Studies probe role of minerals in brain function. Agriculture Research, 49(10), 4. 


\section{Authors}

Dorji Tenzin, M.Ed. is a teacher at Tsangkha Middle Secondary School, Dagana Dzongkhag, Ministry of Education. He has recently completed his Master in Education in Physics from Samtse college of education, Royal University of Bhutan. His research interest includes teaching learning and assessments practices.

Kinley Seden, PhD is a lecturer at the Department of Social Science, Samtse College of Education, the Royal University of Bhutan. Her research interests include psychology of teaching learning and assessment practices, gender and education, teacher education, and professional development.

Nima Dorji, M.Ed. is a teacher at Norbuling Higher Secondary School in Sarpang Dzongkhag under Ministry of Education. His research interest includes education teaching learning and assessments practices, and action research. 